\title{
EFFECT OF REMOVING OLEORESIN WITH VARIOUS CHEMICAL COMPOUNDS ON PHYSICAL AND MECHANICAL PROPERTIES OF KERUING WOOD (DIPTEROCARPUS SPP.)
}

\author{
Bambang Wiyono ${ }^{1}$ and Nurwati ${ }^{1}$
}

\begin{abstract}
Keruing (Dipterocarpus spp.) was the second important wood export of Indonesia. Unfortunately, this wood contains oleoresin that hinders its utilization. Currently, the method used to remove oleoresin from keruing is by soaking it into bollied sodium salt solution. Result of this method is unsatisfactory because the residual heavy oleoresin might still appear on the wood surface. The study was conducted to determine suitable chemical compounds for removing oleoresin from keruing, and the effects on physical and mechanical properties of the wood. Four types of chemical compounds were tested, i.e. sodium chloride, oxalic acid, sulfuric acid, and nitric acid, each at the concentrations of 0.5 percent, 1.0 percent, and 1.5 percent. Wood samples were soaked in the boiling solution at different concentration level for seven hours. When the solution cooled down, the oleoresin exudated out of the wood samples was separated. The oleoresin was weighed for recovery determination after air dried, and the wood samples were cut into smaller-sized specimens for the physical and mechanical testing (MOE, MOR, compression parallel to grain, hardness and density). Results showed that sulfuric acid was the best chemical compound for removing oleoresin, and the higher the concentration the greater the oleoresin recovery. The second best chemical compound was nitric acid at an optimum concentration of one percent. The soaking of keruing in sulfuric acid and oxalic acid solution resulted in paler wood color compare with the untreated wood sample. Nitric acid solutions caused the color of the wood surface to turn into yellow brownish. The physical and mechanical properties (MOE, MOR, compression parallel to grain, hardness and density) of the oleoresin-removed keruing were slightly lower than the untreated (control) samples.
\end{abstract}

Keywords: Keruing, oleoresin, physical and mechanical properties, chemical compound

\section{INTRODUCTION}

Dipterocarpaceae is the most important source of timber in Southeast Asia and constitutes in some producer countries more than half the volume of standing timber. One member of this family is Keruing species, where the distribution of this timber covers Sri Langka, India, Burma throughout Indochina, South China, Thailand, Malaysia and Indonesia. Malay Peninsula, Sumatra and Kalimantan Islands are the center of distribution of this genus. This timber is produced by the approximately 70 species of the genus Dipterocarpus, and in Indonesia itself it is recorded an approximately about 38 species (Boer and Ella, 2001; Kartawinata, 1983).

\footnotetext{
${ }^{1}$ Forest Products Research and Development Center, Bogor
} 
Keruing (Dipterocarpus spp.) is one of the important timbers from Indonesia. These timbers are used for general application, medium to heavy construction materials. Its main application is for interior purposes such as beams, flooring, joists, laboratory furniture, etc. It is also used for rotary-peeled veneer manufacture and for structural plywood, particularly for exterior sheathing and container flooring (Soerianegara and Lemmens, 1994). Unfortunately, this timber contains oleoresins, a mixture of essential oil and resin. This oleoresin fluid is likely to exudate over the surface of freshly cut timber or it appears when the timber is exposed to high temperature, either during kiln drying or in service. This may render sawing and machining difficulties or may cause dark, oily stain on fresh and finished timbers. In the case of very resinous timber, all wood processing operation will be very difficult. To remove oleoresin from timber, several wood industries steamed it prior to further processing. Another method used to remove oleoresin is by soaking timber in a boiling salt solution, in which salt solution is a stimulating agent (Wiyono, 2001). Unfortunately, this method does not work satisfactorily because the remaining oleoresin can still appear. Therefore, a more appropriate use of particular chemical compounds for stimulating agents should be sought to effectively remove the oleoresin.

Relating to the stimulating agent, some chemical compounds, such as sulfate and nitric solutions have been used to stimulate pine resin in tapping activities. With these agents, production of pine resin could be increased significantly (Coppen, Greenhalgh, and Smith, 1984). These agents are also applied in the copal and balsam taping to enhance the flowing rate of copal or balsamic liquid from a wounded trees. Based on this experience, these stimulating agents will be applied for removing oleoresin from keruing timbers. With this respect, the objectives of the research were to find out the proper chemical compounds to remove oleoresin from keruing woods, and to investigate the effect of using these chemical compounds on the physical and mechanical properties of the corresponding timber.

\section{MATERIAL AND METHOD}

The materials in the form of keruing lumbers were obtained from wood industry at Central Kalimantan. At the laboratory in the Forest Products Research and Development Center, the lumbers were cut into small size (32-30 cm length, $12-15 \mathrm{~cm}$ width, and 4-5 cm thickness). These samples were soaked in boiled chemical solution for seven hours. Five kinds of inorganic salt compounds solution were used, i.e. sodium chloride, oxalic acid, sulfuric acid, and nitric acid, each with the concentrations of 0.5 percent, 1.0 percent, and 1.5 percent, respectively. When the boiled solution was cool, the oleoresin coming out from the wood pieces was separated, removed, and the wood were taken out. The oleoresin, after becoming air-dried was weighed for its recovery determination, while the wood pieces were cut to smaller-size specimens for their physical and mechanical testing. The applied physical test was specific gravity based oven-dried; while mechanical test consisted of bending strength (MOE, MOR and within proportional limit) and compression parallel to grain, and side hardness (Karnasudirja, 1987). 


\section{RESULTS AND DISCUSSION}

\section{Keruing oils}

All chemical solution used in this experiment gave the same results. The quantity of oleoresin produced using several chemical compounds in different concentration appeared in Table 1.

Table 1. Oleoresin recovery produced by boiling keruing wood in several chemical compounds

\begin{tabular}{llccc}
\hline \multirow{2}{*}{ No. } & Chemical solution & \multicolumn{3}{c}{ Percentage } \\
\cline { 3 - 5 } & & 0,5 & 1 & 1,5 \\
\hline 1. & Sulfuric acid & 2,38 & 3,59 & 6,98 \\
2. & Nitric acid & 3,04 & 6,33 & 4,71 \\
3. & Oxalic acid & 2,57 & 3,96 & 1,20 \\
4. & Sodium chloride & 1,19 & 3,48 & 3,71 \\
\hline
\end{tabular}

In boiling $0.5 \%$ sulfuric solution, oleoresin of keruing wood came out to the wood surface. At the end of boiling process, some resin floated, and others adhered to the wood. Oleoresin that was removed was black brownish in color, and brittle. Oleoresin yield of this process was about $2.38 \%$. Actually, the yield should be higher, because some resin adhered to the wood which was not easy to separate. This adhered resin on wood could only be removed by plane process. Boiling keruing wood in $1 \%$ sulfuric solution gave similar results. Most of oleoresin that was removed was separated from the wood. It was also brownish in color, and brittle. The oleoresin recovery of boiling keruing wood in $1 \%$ sulfuric solution was about $3.59 \%$, and in $1.5 \%$ solution was about $6.98 \%$.

Boiling in $0.5 \%$ of nitric acid solution, initially oleoresin of keruing wood came out as foam and much adhered to the wood surface. At the end of the boiling process, only a small amount oleoresin was detached from the wood. The oleoresin was brownish in color, and brittle. Oleoresin yield of this process was about $3.04 \%$. This recovery was higher than that removed by using $0.5 \%$ sulfuric acid solution. Boiling keruing wood in $1 \%$ of nitric acid solution removed much more oleoresin. The oleoresin recovery was about $6.33 \%$. Boiling keruing wood in $1.5 \%$ of nitric acid solution produced much more oleoresin on the wood surface. This resin was difficult to separate from the surface. This caused the oleoresin recovery decreased to $4.71 \%$. The oleoresin was brittle and brownish in color. Moreover, when the surface of keruing wood after boiling process was planed, the wood surface color became pale brown.

In the case of boiling $0.5 \%$ oxalic acid solution, much more oleoresin come out and adhered to wood surface. However, this oleoresin was very difficult to detach from the wood surface, but its recovery was still high, about $2.57 \%$. It was brownish in color and brittle. The increase in percentage of oxalic acid solution at $1 \%$ increased its yield to $3.96 \%$. Increasing in $1.5 \%$ oxalic acid solution, seemingly, much more oleoresin was removed and easily separated from the wood surface. In fact, the oleoresin recovery was very low, $1.2 \%$. 
Boiling keruing wood in $0.5 \%$ sodium chloride solution in removed small amount of oleoresin, and this oleoresin easily detached from the wood surface, but its yield was still low, about $1.19 \%$. It was dark-brown in color and breakable. The wood surface after planing was also a little bit dark. The increase in percentage of sodium chloride solution at $1 \%$ increased its yield to $3.48 \%$. Increasing in $1.5 \%$ sodium chloride solution, much more oleoresin was removed, $3.71 \%$ its yield, and easily separated from the wood surface. Moreover, both oleoresin color and the wood surface were also dark-brown.

Among the chemical solution used as stimulating agents, sulfuric acid solution in $1.5 \%$ was the best chemical solution to remove oleoresin from keruing wood. An increase in sulfuric acid concentration removed much more oleoresin. This also occurred when the sodium chloride concentration was increased, but the amount oleoresin remained below that of used nitric acid solution in $1 \%$. Conversely, for nitric solution, an increase in concentration tends to decrease the oleoresin that could be extracted (Figure 1).

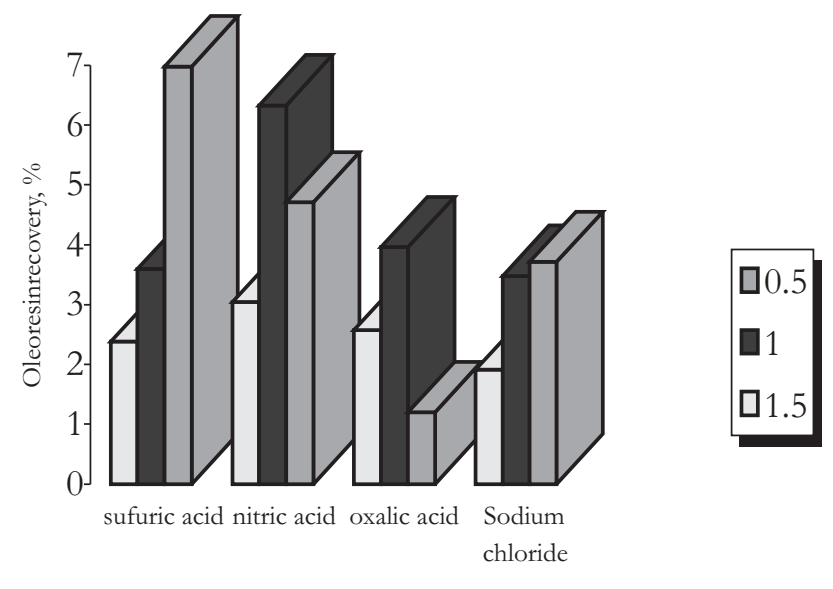

\section{Chemical solution}

Figure 1. Oleoresin recovery at various chemical solution

Oleoresin, a mixture of essential oil and resin, is a source of essential oil production. The essential oil can be separated from resin through extraction using organic solvent (Wiyono, 2001; Jantan, 1988). Therefore, the oleoresin obtained from this extraction was further processed to separate essential oil from resin. Of organic solvents that were tried in this experiment, dichloromethane was the best solvent to dissolve oleoresin, compared to petroleum ether, petroleum benzene, or hexane. Unfortunately, using this solvent to separate essential oil from resin possessed some difficulties, i.e. during centrifuge activities and essential oil separation both essential oil and resin still mixed together. 


\section{Physical and mechanical properties}

To investigate at the effect of oleoresin extraction on wood properties, the wood was tested of its physical and mechanical properties, covering specific gravity, modulus of proportional limit (MPL), modulus of elasticity (MOE), modulus of rupture (MOR), compression parallel to grain, and side hardness. The results are shown in Table 2.

Table 2. Physical-mechanical properties of extracted Keruing wood

\begin{tabular}{|c|c|c|c|c|c|}
\hline \multirow{2}{*}{$\begin{array}{l}\text { Chemical for } \\
\text { extraction }\end{array}$} & \multirow[t]{2}{*}{ Properties } & \multicolumn{4}{|c|}{ Percentage of chemical } \\
\hline & & 0 & 0.5 & 1.0 & 1.5 \\
\hline \multirow[t]{6}{*}{ Sulfate } & $\begin{array}{l}\text { Specific } \\
\text { gravity }\end{array}$ & 0.856 & 0.761 & 0.798 & 0.856 \\
\hline & MPL, $\mathrm{kg} / \mathrm{m}^{2}$ & 400.00 & 150.43 & 257.75 & 123.89 \\
\hline & MOE, $\mathrm{kg} / \mathrm{m}^{2}$ & 66013.31 & 117012.9 & 166381.365 & 61367.36 \\
\hline & MOR, $\mathrm{kg} / \mathrm{m}^{2}$ & 496.90 & 259.78 & 345.81 & 255.06 \\
\hline & $\begin{array}{l}\text { Compression } \\
/ / \text { grain } \\
\mathrm{kg} / \mathrm{m}^{2}\end{array}$ & 344.63 & 261.65 & 269.99 & 239.35 \\
\hline & Hardness, $\mathrm{kg}$ & 247.75 & 180.5 & 157.5 & 87.25 \\
\hline \multirow[t]{6}{*}{ Nitrate } & $\begin{array}{l}\text { Specific } \\
\text { gravity }\end{array}$ & 0.856 & 0.803 & 0.863 & 0.875 \\
\hline & MPL, $\mathrm{kg} / \mathrm{m}^{2}$ & 400.00 & 134.89 & 360.12 & 319.0 \\
\hline & MOE, $\mathrm{kg} / \mathrm{m}^{2}$ & 66013.31 & 52222.81 & 43739.25 & 46035.93 \\
\hline & MOR, $\mathrm{kg} / \mathrm{m}^{2}$ & 496.90 & 344.73 & 267.71 & 345.90 \\
\hline & $\begin{array}{l}\text { Compression } \\
/ / \text { grain } \\
\mathrm{kg} / \mathrm{m}^{2}\end{array}$ & 344.63 & 293.89 & 377.61 & 368.87 \\
\hline & Hardness, $\mathrm{kg}$ & 247.75 & 279.75 & 155 & 171.5 \\
\hline \multirow[t]{6}{*}{ Oxalate } & $\begin{array}{l}\text { Specific } \\
\text { gravity }\end{array}$ & 0.856 & 0.848 & 0.98 & 0.69 \\
\hline & MPL, $\mathrm{kg} / \mathrm{m}^{2}$ & 400.00 & 469.94 & 136.43 & 121.270 \\
\hline & $\mathrm{MOE}, \mathrm{kg} / \mathrm{m}^{2}$ & 66013.31 & 85153.685 & 68248.790 & 31411.60 \\
\hline & $\mathrm{MOR}, \mathrm{kg} / \mathrm{m}^{2}$ & 496.9005 & 590.0515 & 198.6905 & 241.16 \\
\hline & $\begin{array}{l}\text { Compression } \\
/ / \text { grain } \\
\mathrm{kg} / \mathrm{m}^{2}\end{array}$ & 344.63 & 409.70 & 439.02 & 277.60 \\
\hline & Hardness, kg & 247.75 & 358 & 337.75 & 251.5 \\
\hline \multirow[t]{6}{*}{$\mathrm{NaCl}$} & $\begin{array}{l}\text { Specific } \\
\text { gravity }\end{array}$ & 0.856 & 0.781 & 0.830 & 0.879 \\
\hline & MPL, $\mathrm{kg} / \mathrm{m}^{2}$ & 400.00 & 418.32 & 358.91 & 432.70 \\
\hline & MOE, $\mathrm{kg} / \mathrm{m}^{2}$ & 66013.31 & 52610.48 & 46529.98 & 64623.94 \\
\hline & MOR, $\mathrm{kg} / \mathrm{m}^{2}$ & 496.901 & 488.475 & 408.757 & 553.815 \\
\hline & $\begin{array}{l}\text { Compression } \\
/ / \text { grain } \\
\mathrm{kg} / \mathrm{m}^{2}\end{array}$ & 344.63 & 358.87 & 356.38 & 362.42 \\
\hline & Hardness, kg & 247.75 & 355 & 337.5 & 254.75 \\
\hline
\end{tabular}

Remarks: Mean value of twice replication; MOE : modulus of elasticity MPL: modulus of proportional limit, MOR: modulus of rupture 
For the extraction of keruing wood using sulfate, nitrate and $\mathrm{NaCl}$ solutions, the pattern of change inwood specific gravity were almost similar (Table 2 and Figure 2). Wood specific gravity decreased with the use of $0.50 \%$ of those three chemical solutions compared to the control ( $0 \%$ chemical solution). However, the increasing concentration of those chemical solutions from 0.50 to $1.50 \%$ caused remarkable increase in wood specific gravity. With regard to extraction using oxalate solution, appeared to be no different in wood specific gravity between $0.5 \%$ oxalate concentration and the control. At $1.0 \%$ oxalate solution, further, wood specific gravity sharply increased. However, going on to $1.5 \%$, the specific gravity decreased considerably, and revealed the lowest of the overall extracted keruing wood.

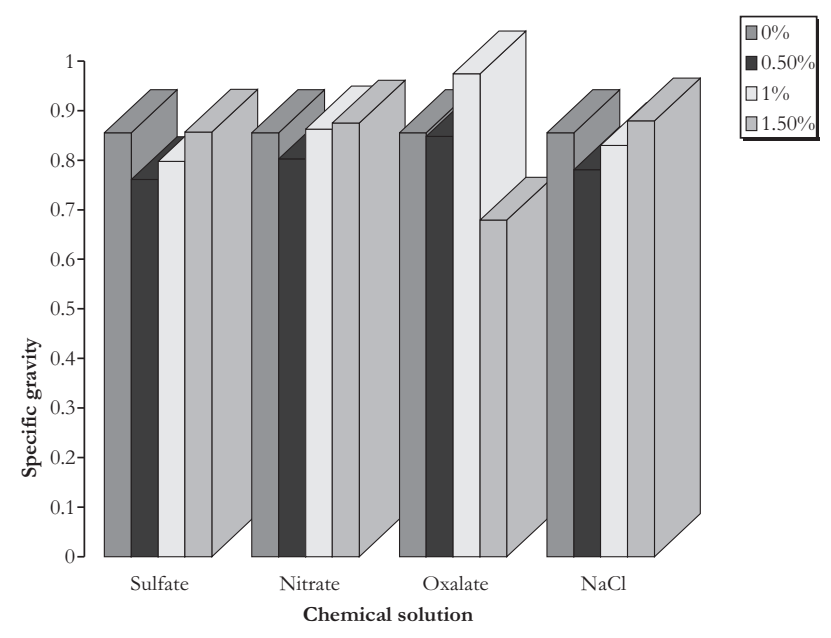

Figure 2. Effect of various kinds of extracting chemical solution and their percentage on specific gravity of extracted keruing wood

Extraction of keruing wood using three kinds of chemical solutions (i.e. sulfate, nitrate and oxalate particularly at $1.5 \%$ ) brought about dramatic decrease in the wood's modulus at proportional limit (MPL) as compared to that of control (Table 2 and Figure 3). The lowest MPL of extracted keruing wood occurred with the use of $1.50 \%$ of oxalate solution. Meanwhile, the use of $\mathrm{NaCl}$ solution at $0.5 \%$ to $1.5 \%$ apparently did not inflict noticeable changes on the MPL, The possible explanation was that sulfate nitrate and oxalate, which are acidic electrolic chemical solutions, could induce chemical degradation on carbohydrate fraction in the wood, hence weakening the wood's strength properties (MPL). These phenomena were also confirmed in the examination on wood specific gravity, whereby in this experiment the MPL turned out to be consistently correlated with wood specific gravity. This also confirmed that the decrease in wood specific gravity due to chemical extraction (particularly sulfate, nitrate and oxalate) significantly reduced the wood strength (MPL). On the other hand, the $\mathrm{NaCl}$ solution is characteristically neutral electrolic chemical solution therefore did not inflict serious effect on the MPL. 


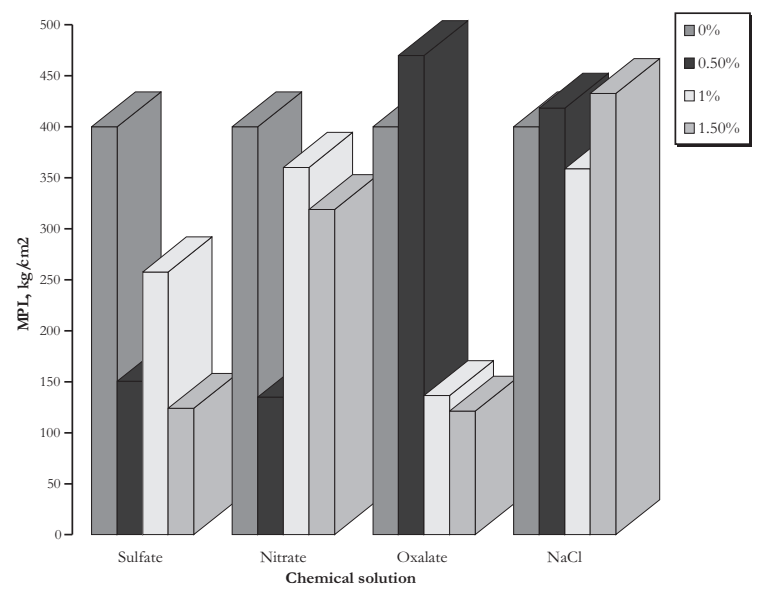

Figure 3. Effect of various kinds of extracting chemical solution and their percentage on MPL of extracted keruing wood

Concerning other wood strength properties (i.e. modulus of elasticity, modulus of rupture, compression parallel to grain and the side hardness) the pattern of changes in those strengths were almost similar to those occurring to the MPL. Likewise, the use of extracting acidic chemical solutions (particularly sulfate, nitrate and oxalate) inflicts deleterious effect on the strengths of extracted keruing wood compared to the control. This implied that such acidic electrolyte solution could harmfully degrade carbohydrate fraction in the wood fiber. Conversely, the use of extracting electrolyte solution with neutral $\mathrm{pH}(\mathrm{NaCl})$ apparently caused no appreciable changes in the wood strengths. In other words, $\mathrm{NaCl}$ electrolyte solution to some extent did not affect the carbohydrate of other fiber chemicals in the wood.

This experiment revealed that the use of acidic electrolyte chemical solution (particularly sulfate, nitrate and oxalate) for wood extraction is tolerable up to $0.5 \%$ concentration, since it only brought about slight decrease in the wood specific gravity and strengths (MPL, MOE, MOR, Compression parallel to grain and side hardness). Meanwhile, the use of $\mathrm{NaCl}$ electrolyte solution is associated with a wider range of use concentration, i.e. up to $1.50 \%$ for extraction of keruing wood. The changes in wood specific gravity due to extraction using various electrolyte solution could be a useful indicator for predicting the altered strengths of the chemically extracted keruing wood.

\section{CONCLUSION}

Sulfuric acid is the best chemical compound for removing oleoresin from keruing timbers. The higher the concentration the greater the oleoresin removed. The second best chemical compound is nitric acid with the optimum concentration of one percent. The soaking of keruing in sulfuric acid and oxalic acid solution resulted in paler wood color as compared to the untreated wood sample. Nitric acid solutions changes the color of the wood surface to yellow brownish. The physical and mechanical properties (MOE, MOR, 
compression parallel to grain, hardness and density) of the oleoresin-removed keruing wood were slightly lower than the untreated (control) samples.

Based on the specific gravity of extracted-wood, which is the most important indicator wood quality for a building material and is closely correlated with other physical properties as well as most strength properties, all chemical substances with $1.5 \%$ could be used to extract keruing oil from wood, with an exception oxalic acid should not be used with a concentration higher than $1.0 \%$.

\section{LITERATURE}

Boer, E. and A. B. Ella. 2001. Plant Producing Exudates. Plant Resources of South East Asia No: 18. Prosea Bogor, Indonesia.

Coppen, J. J. W., P. Greenhalgh, and A. E. Smith. 1984. Gum Naval Stores: an industrial profile of terpentine and resin production from pine resin. Tropical Development Research Institute. London.

Karnasudirdja, S. 1987. Pengetahuan Bahan Kayu. Sifat fisis dan mekanis. Departemen Kehutanan. Pusat Penelitian dan Pengembangan Hasil Hutan. Bogor.

Kartawinata, K. 1983. Jenis- jenis Keruing. LBN-28. LIPI.

Soerianegara, I and R. H. M. J. Lemmens. 1994. Timber Trees: Major commercial timbers. Plant Resources of South-East Asia, No. 5. Bogor-Indonesia.

Wiyono, B. 2001. Keruing wood and oleoresin residues as a source of raw material for essential oil production. Proceedings of Symposium on Utilization of Agricultural and Forestry Residues, October 31-Nopember 3, 2001. Nanjing China. 